\section{Abstract \\ A country's history and}

development can be shaped by its natural environment and the hazards it faces. As a response to the threat of novel and unexpected bushfire disasters, scholars and practitioners have turned to the area of artificial intelligence. This paper explores the underlying principles of artificial intelligence tools and to investigate how these tools have been used to mitigate the risks of catastrophic bushfires. In doing so, this research provides an overview of applications of artificial intelligence tools to enhance effective management of bushfires through preparedness capability, responding capability and recovery capability. The future evolution of tools in artificial intelligence is discussed in the bushfire management context based on emerging trends.

\title{
Implications of artificial intelligence for bushfire management
}

Peer Reviewed

\section{Dr Seyed Ashkan} Zarghami $^{1}$

\section{Dr Jantanee Dumrak ${ }^{1}$}

1 Torrens University, Adelaide, South Australia.

\section{SUBMITTED}

28 September 2020

\section{ACCEPTED}

11 November 2020

Permissions information for use of this content can be found at https://knowledge. aidr.org.au/ajem

https://doi.org/ 10.47389/36.1.84

\section{Introduction}

Australia has a long history of bushfires and the most recent bushfire disaster of 2019-20 will not be the last. Bushfires can be tragic but, at the same time, are regular events in many parts of the country. As a response to the threat of bushfire, emergency management policies in Australia have pushed the concept of bushfire management as a means of mitigating bushfire risks (Philips et al. 2016). However, the conventional view of bushfire management may no longer be sufficient to cope with the increasing complexity of bushfire disasters (Linnenluecke \& Griffiths 2013). The traditional approach advocates for the use of qualitative methodologies to obtain knowledge and an understanding of the issues surrounding the bushfire disaster (Pooley, Cohen \& O'Connor 2010). However, the qualitative view of bushfire management partially analyses interactions between people, resources and the environment (Minas, Hearne \& Handmer 2010). This perspective fails to provide a complete representation of complex interactions between the elements of complex natural systems exposed to recurring bushfires. The necessity for the development and delivery of an effective bushfire management framework that can deal with novel and unexpected threats has motivated scholars and practitioners to turn to the area of artificial intelligence (Al). Modern computing allows Al to be used as an effective tool to support disaster and recovery operations. However, there is a lack of research on how Al has been applied in bushfire management. The objective of this work is to explore the current state of the science in applying Al to bushfire management practice. This paper offers a lens through which researchers and practitioners might better understand key concepts and links of Al to the functional areas of bushfire management.

The practice of bushfire management is conceptualised as a set of capabilities that provide a reliable recovery process and a minimal adverse consequence when bushfires occur. Three distinct stages in bushfire management are used and each stage addresses the required capabilities for effective management, being:

preparedness capabilities are the abilities to prepare for disruptive events to reduce the detrimental effects of natural disasters (Madni \& Jackson 2009) 
M RESEARCH

- responding capabilities are the abilities to develop solutions to resist destruction when an unexpected event occurs (Jaques 2007)

- recovery capabilities refers to adjustments in the aftermath of crises (Limnios et al. 2014), which helps the affected community to recover.

The key contribution of this study is to provide an overview of example applications of $\mathrm{Al}$ tools to enhance the 3 capabilities of preparedness, response and recovery.

\section{A synopsis of artificial intelligence}

It is common to think of $\mathrm{Al}$ as a relatively modern concept in computer science. However, the concept of Al can trace its origin to the $8^{\text {th }}$ Century BC in The Iliad, an epic poem by the Greek poet Homer. In this poem, Homer portrayed Hephaestus, the god of fire, as an inventor who built golden automata, or self-operating machines (Abbott 2020). 'Artificial intelligence' as a term was first coined by John McCarthy in 1956 at the second Dartmouth conference. Since the first use of the term Al, the understanding of what Al entails and how it is designed has evolved. There is no universally accepted definition of Al. However, modern definitions have been widened in line with the definition suggested by Russell and Norvig (2016) as 'the designing and building of intelligent agents that receive precepts from the environment and take actions that affect the environment'.

With the advent of modern computers, there is a rise in the employment of Al based methods. These methods have traditionally been classified into 2 paradigms: Symbolic Al and Connectionist Al. Symbolic Al develops computational models to mimic human expertise on the basis of symbol representation (Sun 2015). In this approach, the modeller generates rules for software to follow (Abbott 2020). Examples of methods used in this approach are fuzzy logic and Bayesian networks. Connectionist Al focuses on learning. This approach involves the adjustment of weights in a large network of units. In this approach, unlike the symbolic Al, the modeller does not specify the rules of the phenomenon under scrutiny. The rules are generated by computers based on learning from examples (Abbott 2020). Machine learning, artificial neural networks and deep learning are examples of the most widely used tools in this paradigm.

\section{Research methodology}

An integrative literature review was performed to summarise the research on the applications of $\mathrm{Al}$ in the bushfire management context. In conducting the integrative literature review, an iterative approach was adopted to define appropriate keywords, analyse and synthesise data and finalise the classification results (see Figure 1).

Step 1 - Identifying data sources: An initial search was conducted using Google Scholar, EBSCOhost and the Scopus citation database. The articles were mainly obtained from the publishers including Emerald, Elsevier, Taylor \& Francis, Springer, CSIRO Publishing, the Australian Institute of Disaster

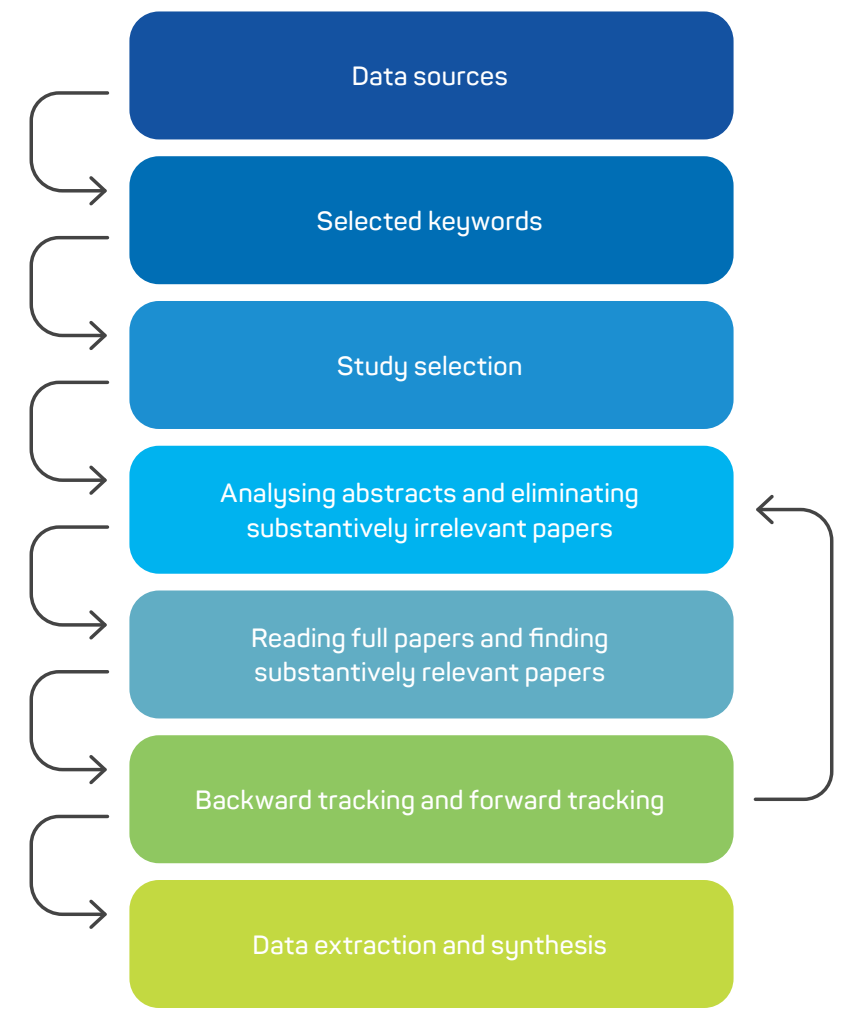

Figure 1: Schematic diagram of the research methodology.

Resilience, the Australian Emergency Management Institute and Canadian Science Publishing. In order to provide a coherent sequence of the development of the Al tools in bushfire management, the span of time over which the research articles were published was not restricted. The final list of papers in this work contained 34 articles from 2000 to 2020.

Step 2 - Search methodology: The search methodology was based on selected keywords including 'bushfire', 'wildfire', 'artificial intelligence', 'fire suppression', 'disaster management', 'fuel treatment', 'post-disaster', 'prediction', 'emergency evacuation' and 'emergency relief'. Boolean operators 'AND' and 'OR' were used to combine the keywords. For instance, one such combination was 'bushfire OR wildfire AND artificial intelligence'.

Step 3 - Study selection and evaluation: Substantively irrelevant papers were eliminated by reviewing the abstracts of the identified papers in Step 2. The remaining papers were then read in their entirety to ensure substantive relevance. Further, backward-tracking was used to find the relevant papers that were cited and forward-tracking was used to find the relevant articles that cited the central source. This helped to find papers that were not identified through the search process. 
Step 4 - Data extraction and synthesis: The findings of each individual study were synthesised into different arrangements based on different stages of bushfire management. Information from each paper was organised under the 3 main categories of preparedness capabilities, responding capabilities and recovery capabilities.

\section{Applications of $\mathrm{Al}$ in bushfire management}

To illustrate how Al can enhance bushfire management practice, $16 \mathrm{Al}$ tools and 7 application areas were identified within the 3 stages of bushfire management (see Figure 2).

\section{Preparedness capabilities}

Al tools are effective in the prediction and prevention of bushfires. In this stage, the ultimate goal of using Al is to improve preparedness capabilities to prepare communities and fire agencies for unprecedented events. Al possesses 2 desirable features; it can be used to characterise and map susceptibility to bushfires through predictive modelling techniques, and it can provide tools for establishing an effective fuel treatment system.

\section{Bushfire predication}

Rooted in $\mathrm{Al}$, an array of methods has been developed to predict the likelihood and spatial pattern of bushfire occurrence. For example, Zhang, Lim \& Sharples (2016) developed a Logistic Regression Analysis model to generate a fire occurrence probability map for south-eastern Australia. Thompson (2013) built a Markov chain model to predict the location and timing of fire events in the USA. Massada and colleagues (2013) used machine-learning algorithms to develop an ignition-distribution method. The proposed method aimed to predict the likelihood of fire occurrence across Huron-Manistee National Forest in
Michigan, USA. Adab (2017) adopted artificial neural networks to evaluate the potential of bushfire hazards based on the frequencies and distributions of bushfires in Golestan Province in Iran.

\section{Fuel treatment}

Reducing hazardous fuels is a primary objective of fuel treatment. The commonly used fuel treatment methods are commercial timber harvest, mechanical thinning, mastication and prescribed burning. Many studies have explored the potential of using Al in fuel treatment planning. These studies have investigated a range of decision making paradigms to find optimal solutions for locating fuel treatment resources, scheduling fuel treatment activities and economic efficiency. Wei, Rideout and Kirsch (2008) employed Mixed Integer Programming to find the optimal locations of fuel treatment resources in the USA. Kim, Bettinger and Finney (2009) attempted to optimise the scheduling of fuel treatment activities in Oregon, USA by means of the Great Deluge algorithm. Konoshima and colleagues (2010) developed a stochastic dynamic programming model for the cost-efficient allocation of fuel treatment with the intent of optimising fuel management decisions.

\section{Responding capabilities}

Al can be used to enhance responses to bushfire. In this stage, researchers and fire agencies have used Al to achieve 2 objectives:

- to safely contain and suppress bushfires as quickly and effectively as possible

- to prevent bushfire fatalities and injuries by developing and implementing an effective emergency evacuation and rescue plan.

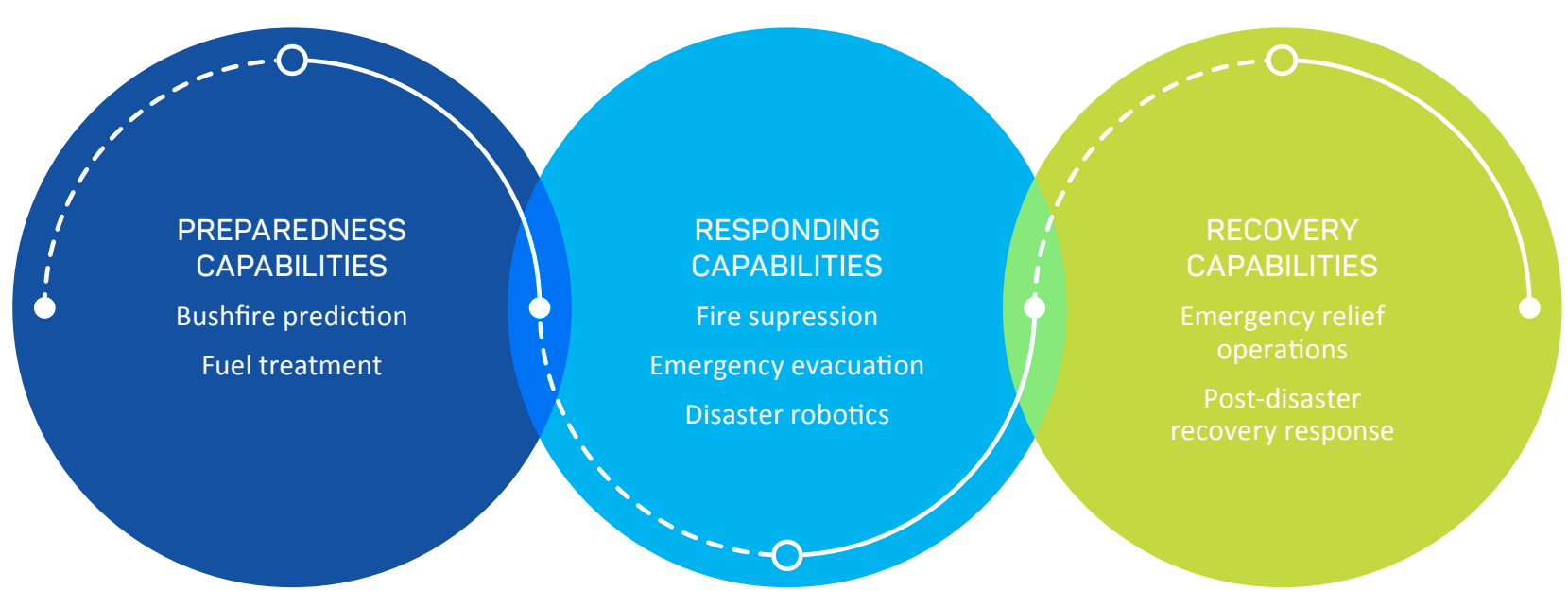

Figure 2: The 3 stages of bushfire management and their 7 application areas. 


\section{Fire suppression}

Researchers have successfully introduced a range of Al tools to manage fire suppression activities. Two common types of fire suppression activities are:

- initial attack that prevents the further extension of the fire

- extended attack that refers to the actions taken for the bushfire that has not been contained by initial attack forces.

In this context, Al has been employed to minimise the extent of the uncontained fire, thereby improving the effectiveness of initial attack activities. Various optimisation methods have been used to determine the optimal time, location and deployment of the initial attack resources. Furthermore, Al has been applied to solve the problem of scheduling firefighting resources. For example, Hof and colleagues (2000) proposed a linear programming model to delay the timing of fire spread for the bushfire events that exceed containment capabilities of suppression resources. Haight and Fried (2007) constructed an integer programming model for the optimal deployment of fire suppression resources in California, USA. Rachaniotis and Pappis (2011) adopted heuristic algorithms to address the problem of scheduling firefighting resources when fire escapes initial attack. Hansen (2012) used regression analysis to quantify the quantity of water required to suppress the fire by taking into account the fire suppression time, the size of the affected bushfire area and the flame height.

\section{Emergency evacuation}

Evacuation of people within a restricted time window is a major concern for fire services and emergency management organisations. To date, most literature on emergency evacuation advocates the use of optimisation methods for planning evacuation during bushfires. Rui, Shiwei and Zhang (2009) used a genetic algorithm to develop an evacuation plan to minimise the total evacuation time in the city of Gulfport, USA. Kulshreshta, Lou and Lim (2014) optimised the use of public transportation in emergency evacuation planning by employing Tabu search heuristic. In particular, the authors determined the optimal pickup locations and bus allocations for emergency evacuation in South Dakota, USA. Shahparvari, Abbasi and Chhetri (2017) proposed a vehicle routing problem approach to facilitate evacuation of short-notice evacuees during a bushfire in Victoria, Australia.

\section{Disaster robotics}

Disaster robotics including unmanned ground vehicles and unmanned aerial vehicles are currently the most promising and safe methods for response and rescue operations. At the most basic level, robotics technology is used for mapping affected communities, firefighting, search and rescue (Sun, Bocchini \& Davision 2020). Significant advances in robotics technology can be credited to the use of machine-learning techniques for acquiring new robotics skills and deep-learning tools for visual detection.

\section{Recovery capabilities}

Al has propelled research into the recovery stage of bushfire management with the aim of returning communities to normal. In practice, Al has been widely adopted to assist communities to recover from bushfire disasters.

\section{Emergency relief operations}

Al tools have been used to facilitate post-disaster relief operations. Specifically, Al methods help to develop decisionsupport systems for the humanitarian supply chain. For example, Wei and Kumar (2007) used the ant colony optimisation technique to solve logistics problems of relief activities. The outputs of the proposed method intended to minimise the delay in transportation of commodities from suppliers to distribution centres in disaster affected areas. Lei and colleagues (2015) adopted the rolling horizon heuristics method to optimise the scheduling of medical teams and the provision of medical supplies for New York with a network of 80 hospitals. Bodaghi and colleagues (2020) developed an emergency operation model drawing on mixed integer programming to assist in scheduling and sequencing multiple resources in a Victorian bushfire case study.

\section{Post-disaster recovery response}

To address the recovery needs of affected communities, Al tools have been applied in the post disaster recovery phase. Öztayși and colleagues (2013) proposed a volunteer management framework using fuzzy logic for the recovery process in Greece. Lin and Wang (2017) employed a Markov Chain model for the recovery process for a portfolio of community buildings. Sublime and Kalinicheva (2019) used deep-learning techniques to create post-disaster damage mapping following natural disasters in Japan. Raza and colleagues (2020) used a machine-learning model to facilitate communications between emergency services organisation and affected communities.

\section{The roadmap for the future applications of $\mathrm{Al}$ in bushfire management}

Since 2000, there has been major progress in the application of Al-based methods in bushfire management. Figure 3 illustrates the applications of Al tools in various stages of bushfire. Among these methods, the optimisation tools have received considerable attention. One explanation for this can be that fire agencies are confronted with a plethora of choices to optimise objective functions. This has propelled research to find the best solutions to achieve objectives such as optimal allocation of constrained resources for fire suppression and optimal allocation of response personnel.

Based on emerging trends in the application of $\mathrm{Al}$ in bushfire management, there are other possible future applications that would provide benefit. 
Table 1: Applications of Al tools in different functional areas of bushfire management.

\begin{tabular}{|c|c|c|c|}
\hline Application & Location & Method & Author(s) \\
\hline $\begin{array}{l}\text { Modelling spatial patterns of } \\
\text { bushfire occurrence }\end{array}$ & South-eastern Australia & Regression Analysis & Zhang, Lim \& Sharples (2016) \\
\hline Bushfire distribution modelling & Michigan USA & Machine Learning & Massada et al. (2013) \\
\hline Modelling bushfire complexity & USA & Markov Chain Model & Thompson (2013) \\
\hline $\begin{array}{l}\text { Frequency and distribution of } \\
\text { bushfires }\end{array}$ & Iran & Artificial Neural Network & Adab (2017) \\
\hline $\begin{array}{l}\text { Locating fire treatment } \\
\text { resources }\end{array}$ & California USA & Mixed Integer Programming & Wei, Rideout \& Kirsch (2008) \\
\hline $\begin{array}{l}\text { Optimisation of fuel treatment } \\
\text { activities }\end{array}$ & Oregon USA & Great Deluge Algorithm & Kim, Bettinger \& Finney (2009) \\
\hline $\begin{array}{l}\text { Optimal pattern of fuel } \\
\text { treatment and harvesting }\end{array}$ & Hypothetical & $\begin{array}{l}\text { Stochastic Dynamic } \\
\text { Programming }\end{array}$ & Konoshima et al. (2010) \\
\hline Delaying ignition time & Hypothetical & Linear Programming Model & Hof et al. (2000) \\
\hline $\begin{array}{l}\text { Deploying and dispatching fire } \\
\text { suppression resources }\end{array}$ & California USA & Integer Programming Model & Haight \& Fried (2007) \\
\hline Scheduling firefighting resources & Hypothetical & Heuristic Algorithms & Rachaniotis \& Pappis (2011) \\
\hline $\begin{array}{l}\text { Estimating bushfire suppression } \\
\text { resources }\end{array}$ & Hypothetical & Regression Analysis & Hansen (2012) \\
\hline $\begin{array}{l}\text { Determining pickup locations } \\
\text { and bus allocations for } \\
\text { emergency evacuation }\end{array}$ & South Dakota USA & Tabu Search Heuristic & Kulshreshta, Lou \& Lim (2014) \\
\hline $\begin{array}{l}\text { Optimising transit evacuation } \\
\text { plan }\end{array}$ & Gulfport USA & Genetic Algorithm & Rui, Shiwei \& Zhang (2009) \\
\hline $\begin{array}{l}\text { Scheduling for short-notice } \\
\text { bushfire emergency evacuation }\end{array}$ & Victoria Australia & Vehicle Routing Problem & $\begin{array}{l}\text { Shahparvari, Abbasi \& Chhetri } \\
\text { (2017) }\end{array}$ \\
\hline $\begin{array}{l}\text { Solving logistics problems for } \\
\text { disaster relief activities }\end{array}$ & Hypothetical & Ant Colony Optimisation & Wei \& Kumar (2007) \\
\hline $\begin{array}{l}\text { Personnel scheduling and } \\
\text { supplies provisioning in } \\
\text { emergency relief operation }\end{array}$ & New York USA & Rolling Horizon Heuristics & Lei et al. (2015) \\
\hline $\begin{array}{l}\text { Scheduling of multiple resources } \\
\text { for emergency operations }\end{array}$ & Victoria Australia & Mixed Integer Programming & Bodaghi et al. (2020) \\
\hline Volunteer management & Greece & Fuzzy Logic & Öztayși et al. (2013) \\
\hline $\begin{array}{l}\text { The recovery process of } \\
\text { community building portfolios }\end{array}$ & Hypothetical & Markov Chain Model & Lin \& Wang (2017) \\
\hline Post-disaster damage mapping & Japan & Deep Learning & Sublime \& Kalinicheva (2019) \\
\hline $\begin{array}{l}\text { Communication between } \\
\text { emergency service authorities } \\
\text { and communities }\end{array}$ & Hypothetical & Machine Learning & Raza et al. (2020) \\
\hline
\end{tabular}


" RESEARCH

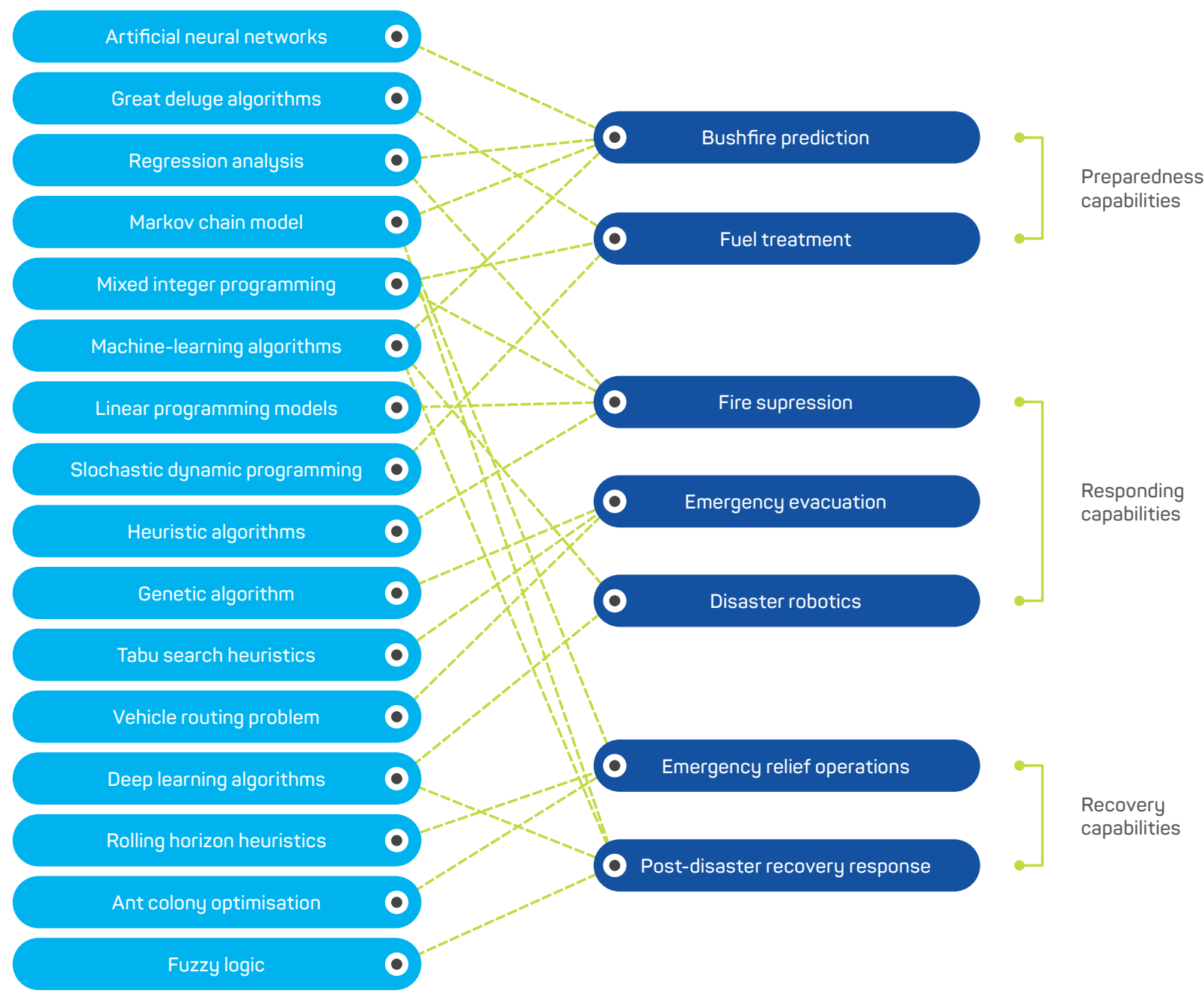

Figure 3: Current applications of Al tools in bushfire management.

Many activities in bushfire risk mitigation are concerned with the prediction and projection of elements such as predicting the amount of time for fire suppression and forecasting the behaviour of bushfires. As such, most of the decision-making for bushfire management takes place under conditions of uncertainty. This uncertainty can be managed when Al methods are used in conjunction with human intuition and judgement. Smith (2016) argued that the human, as the final decision maker, should have a pronounced presence in the next generation of $\mathrm{Al}$ tools. The strength of human decision making lies in the ability to take new and innovative actions in uncertain environments.

The connectionist Al paradigm is gaining attention in bushfire management compared to the symbolic Al paradigm. Although the connectionist models have helped emergency managers to make decisions, these models do not account for human cognition. Moreover, the connectionist methods are datasensitive and require a vast amount of structured training data. The function of robots used in bushfire preparedness and response operations are restricted to the specific problem applications that they are designed for. These shortcomings render the use of purely connectionist methods as ineffective. Given the different strengths of connectionist and symbolic paradigms, the applications of hybrid methods that combine 2 paradigms are likely in the near term. An example of successful hybridisation of Al is Google's search engine in which sentence transformers (connectionist Al) are coupled with the knowledge graph reasoning tools (symbolic Al). The successful implementation of hybrid Al tools can trigger the development of hybrid methods usable in the bushfire management context.

Bushfires exhibit unique characteristics not shared by other events and bushfire management requires specific types of predication, mitigation and recovery activities. Existing Al tools lack the function-specific capabilities required to minimise the harmful effects of bushfires. Despite Al being reliant on training data as human input, it does not replace human judgement. This highlights the need for new perspectives on the development of new function-specific Al tools that are fine-tuned using both training data and the human judgement of bushfire experts. 
M RESEARCH

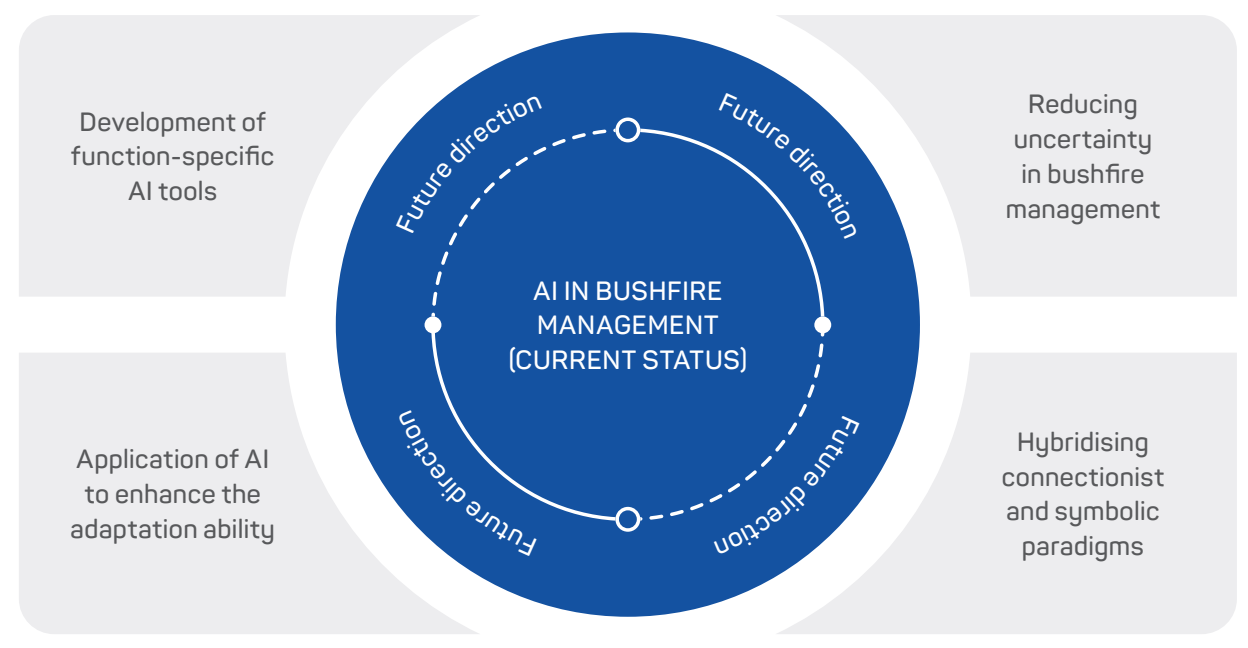

Figure 4: A roadmap of future applications of $\mathrm{Al}$ in bushfire management.

There is a paucity of research on adaptation to bushfire including long-term learning, which enables communities to develop new norms through lessons learnt from past events. Adaptation is indeed the main antecedent for the anticipation dimension of resilience in disaster management (Duchek 2020). The few existing studies are predominately anecdotal and descriptive. Future research could harness Al potential to incorporate insight from bushfire disasters into the knowledge base of fire service agencies and government departments. The knowledge-based platforms, which house information on historical bushfire disasters, can be assisted by the development of Al-focused hubs that tap the benefit of this technology.

Figure 4 is a schematic of future prospects for the applications of $\mathrm{Al}$ in bushfire management.

\section{Conclusions}

The aim of this paper was to answer the question: What is the current state of the science of applying Al to enhance bushfire management practice? A review of research on the applications of $\mathrm{Al}$ in the bushfire management context was undertaken. Three distinct perspectives were identified on the resilience capabilities of bushfire management practices and analysis provided an overview of links between $\mathrm{Al}$ and resilience capabilities.

This overview indicated that bushfire management has benefited from the applications of Al over the past 2 decades and it has resulted in several novel methods that mitigate the risk of catastrophic bushfires. Future bushfire scholars and practitioners will be encouraged to develop and implement function-specific Al methods. Bushfires exhibit unique behaviour and the development and implementation of function-specific Al tools will provide insight into the unique characteristics of fire behaviour and progression. The growing complexity of bushfires, as well as other hazard events, reinforces the need to manage this complexity using new methods as well as the next generation of Al tools.

\section{References}

Abbott R 2020, The Reasonable Robot: Artificial Intelligence and the Law, Cambridge University Press, Cambridge, UK.

Adab H 2017, Landfire hazard assessment in the Caspian Hyrcanian forest ecoregion with the long-term MODIS active fire data, Natural Hazards, vol. 87, no. 3, pp.1807-1825.

Bodaghi B, Palaneeswaran E, Shahparvari S \& Mohammadi M 2020, Probabilistic allocation and scheduling of multiple resources for emergency operations; a Victorian bushfire case study, Computer, Environment and Urban Systems, vol. 81, pp.101479: 1-16.

Duchek S 2020, Organizational resilience: a capability-based conceptualization, Business Research, vol.13, no. 1, pp.215-246.

Haight RG \& Fried JS 2007, Deploying wildland fire suppression resources with a scenario-based standard response mode, INFO: Information Systems and Operational Research, vol. 45, no.1, pp.31-39.

Hansen R 2012, Regression analysis of wildfire suppression, WIT Transactions on Economy and Environment, vol. 158, pp.213-223.

Hof J, Omi P, Bevers M \& Laven R 2000, A timing-oriented approach to spatial allocation of fire management effort, Forest Science, vol. 46, no. 3, pp.442-451.

Jaques T 2007, Issue management and crisis management: An integrated, non-linear, relational construct, Public Relations Review, vol. 33, no. 2, pp.147-157.

Kim YH, Bettinger P \& Finney M 2009, Spatial optimization of the pattern of fuel management activities and subsequent effects on simulated wildfire, European Journal of Operational Research, vol. 197, no. 1, pp.253-265.

Konoshima M, Albers H, Montgomery C \& Arthur J 2010, Optimal spatial patterns of fuel management and timber harvest with fire risk, Canadian Journal of Forest Research, vol. 40, no. 1, pp.95-108.

Kulshreshta A, Lou Y \& Yin Y 2014, Pick-up locations and bus allocation for transit-based evacuation planning with demand uncertainty, Journal of Advanced Transportation, vol. 48, no. 7, pp.721-733.

Lei L, Pinedo M, Qi L, Wang S \& Yang J 2015, Personnel scheduling and supplies provisioning in emergency relief operation, Annals of Operations Research, vol. 235, no. 1, pp.487-515. 
Limnios EAM, Mazzarol T, Ghadouani A \& Schilizzi SG 2014, The resilience architecture framework: Four organizational archetypes, European Management Journal, vol. 32, no. 1, pp.104-117.

Lin P \& Wang N 2017, Stochastic post-disaster functionality recovery of community building portfolios, Structural Safety, vol. 69, pp.96-105.

Linnenluecke MK \& Griffiths A 2013, The 2009 Victorian Bushfires: A Multilevel Perspective on Organizational Risk and Resilience, Organization \& Environment, vol. 26, no. 4, pp.386-411.

Madni AM \& Jackson S 2009, Towards a conceptual framework for resilience engineering, IEEE Systems Journals, vol. 3, no. 2, pp.181-191.

Massada AB, Syphard AD, Stewart SI \& Radeloff VC 2013, Wildfire ignition distribution modelling: a comparative study in the Huron-Manistee National Forest, Michigan, USA, International Journal of Wildland Fire, vol. 22, no. 2, pp.174-183.

Minas JP, Hearne JD \& Handmer J 2010, A review of operations research methods applicable to wildfire management, International Journal of Wildland Fire, vol. 21, no. 3, pp.181-196.

Öztayși B, Behret H, Kabak Ö, Sari IU \& Kahraman C 2013, Fuzzy inference systems for disaster response, in Vitoriano B, Montero de Juan J\& Ruan D (Eds), Decisions Aid Models for Disaster Management and Emergencies, Atlantis Press, Paris, France: pp.75-94.

Philips R, Cook A, Schauble H \& Walker M 2016, Can agencies promote bushfire resilience using art-based community engagement, Australian Journal of Emergency Management, vol. 31, no. 4, pp.51-55.

Pooley JN, Cohen L \& O'Connor M 2010, Bushfire communities and resilience: What can they tell us?, Australian Journal of Emergency Management, vol. 25, no. 2, pp.33-38.

Rachaniotis NP \& Pappis CP 2011, Minimizing the total weighting tardiness in wildfire suppression, Operational Research, vol. 11, no. 1, pp.113-120.

Raza M, Awais M, Ali K, Aslam N, Paranthaman VV, Imran M \& Ali F 2020, Establishing effective communications in disaster affected areas and artificial intelligence based detection using social media platform, Future Generation Computer Systems, vol. 112, pp.1057-1069.

Rui S, Shiwei HE \& Zhang L 2009, Optimum transit operations during the emergency evacuation, Journal of Transportation Systems Engineering, vol. 9, no. 6, pp.154-160.

Russell SJ \& Norvig P 2016, Artificial Intelligence: A Modern Approach, Pearson Education Limited (3rd edition), Essex, England.

Sublime J \& Kalinicheva E 2019, Automatic post-disaster damage mapping using deep-learning techniques for change detection: Case study of Tohoku Tsunami, Remote Sensing, vol. 11, no. 9, pp.1123: 1-20.

Shahparvari S, Abbasi B \& Chhetri P 2017, Probabilistic scheduling routing for short-notice bushfire emergency evacuation under uncertainties, An Australian case study, Omega, vol. 72, pp.96-117.

Smith RE 2016, Idealization of uncertainty and lessons from artificial intelligence, Economics: The Open-Access, Open-Assessment E-Journal, vol. 10, no. 2016-7, pp.1-40.

Sun R 2015, Artificial intelligence: Connectionist and symbolic approaches, International Encyclopaedia of the Social\& Behavioral Sciences, Second edition, vol. 2, pp.35-40.

Sun W, Bocchini P \& Davision BD 2020, Applications of artificial intelligence for disaster management, Natural Hazards, pp.1-59. doi.org/10.1007/s11069-020-04124-3

Thompson MP 2013, Modeling wildfire incident complexity dynamics, Plos One, vol. 8, no. 5, pp.e63297: 1-10.
Wei Y \& Kumar A 2007, Ant colony optimization for disaster relief operations, Transportation Research Part E: Logistics and Transpiration Review, vol. 43, no. 6, pp.660-672.

Wei Y, Rideout D \& Kirsch A 2008, An optimization model for locating fuel treatment across a landscape to reduce expected fire losses, Canadian Journal of Forest Research, vol. 38, no. 4, pp.868-877.

Zhang Y, Lim S \& Sharples JJ 2016, Modelling spatial patterns of wildfire occurrence in South-Eastern Australia, Geomatics, Natural Hazards and Risk, vol. 7, no. 6, pp.1800-1815.

\section{About the authors}

Dr Seyed Ashkan Zarghami is a Lecturer and Research Fellow at Torrens University. He completed his PhD in Complex Systems at the University of Adelaide. His research interests include project management, system engineering, reliability analysis and operations management.

Dr Jantanee Dumrak is Program Coordinator and Senior Lecturer at Torrens University. She completed her Doctorate in Project Management at the University of South Australia. 